\title{
Study on How to Adapt Raw Clay Housing to Climate Change: Locust Bean Tree (Parkia Biglobosa) Used as Protecting Material
}

\author{
Samah Ouro-Djobo Essoavana ${ }^{1}$, Amey Kossi Bollanigni ${ }^{1}$, Sanya Emile ${ }^{2}$, Vianou Antoine ${ }^{2}$ and Atcholi Esso \\ Kokou $^{3}$ \\ 1. Building and Housing Centre, National High School of Engineers, University of Lomé, Lomé 20 564, Togo \\ 2. Industrial Vocational Study and Research Laboratory, Abomey Calavi University, Cotonou 00229, Bénin \\ 3. Department of Mechanical Engineering and Design, University of Technology of Belfort-Montbeliard, Belfort 90010, France
}

\begin{abstract}
The use of raw clay in housing construction dates back from ancient times and is still living on. Traditional habitat comprising various buildings all over different places of our planet, give evidence. Among any other pathologies affecting naked earthen walls, the rain water wash remains a major concern and deserves careful consideration. Which justifies the interest of this research focused on the protection means of such types of walls. This article relates the experiment conducted on low walls made out of raw clay mixed with composite protecting products (traditional and modern ones as well), being tested to intensive water floods. The result of the tests assessed through efficiency of the protecting materials, shows that the locust bean tree (local tree) fruit husk extract added to raw clay mortar and carefully blended seems to provide better ability to protect walls against water assault. Moreover, consistency check and plasticity reveal better performance in clay material properties.
\end{abstract}

Key words: Clay material, protection, locust bean tree, consistency, plasticity.

\section{Introduction}

Soil is a building material better adapting to hot tropical climates. Clay mortar has heat isolation properties and is resilient to tensile strength depending on using conditions. The directions for handling of the material has evolved, thus entailing development in moulding techniques, ranging from the most rudimentary ones (manual and skilled as well) to the most sophisticated ones (mechanical and industrial ones). The portion of the world population dwelling in clay houses is estimated at $30 \%$ or more [1]. Besides, $17 \%$ of UNESCO world heritage are clay building works [2].

In Togo and Benin, housing constructions account for $70 \%$ [3]. The percentage is much higher in rural

Corresponding author: Samah Ouro-Djobo Essoavana, assistant professor, assistant researcher, research fields: civil engineering, energy and environment. E-mail: odsamah@yahoo.fr. areas because it covers equipments and lodgings as well.

As far as buildings and cultural structures are concerned, soil is now and for long time to come the basic material of the rural Togolese and Beninese self contractors. Therefore, protection issue of earthen buildings is, and remains a major concern, facing climate change phenomenon which brings about higher precipitations. The interest of this study on earthen buildings resides in the poor resilience of conventional habitats to bad weather and the subsequent ever recurring repairs. Nevertheless, those habitats represent sometimes a cultural expression to be saved as is the case with Tata Tamberma in the north of Togo, totally made out of raw clay and classified as UNESCO world heritage [3]. Indeed, a review of former studies reveals that local miscellaneous coating materials have been used on raw clay walls to protect against bad weather 
and assaults [2-5].

Current practice composites include: straw-stabilised soil, cow dung, various cement-binding materials, lime, bitumen, coal tar; in Togo and Benin mortars (cement/sand: 1/15 blend), in India cement mortar (in two layers of different dosing), in Burkina Faso painting of walls with banana peels' and leaves' porridge in Ghana. The coal tar resists for 10 years or so, but cracks away and loses protection efficiency. Its black coloration favours solar heat accumulation, spreading to the walls and seeping into the premises. Somewhere, kneaded clay is successfully applied to the woody frame of the premises to strengthen walls. The ceilings' edges are also extended to prevent water assault. Sometimes veranda laying is one more alternative. Indeed, all those practices have been done but relatively successful. The major constraints often remain the renovation of the protection material, for even the cement mortars can loosen from earthen walls [2].

Application of each method depends on the location and the degree of technological control by the local craftsmen (5). Among existing solutions the sustainable ones are often costly, thus out of reach of the poorest African populations. An in-depth study deserves being devoted to research on efficient and long lasting means of protection of clay structures and on the best ways of making use thereof.

It is then pressing to find materials likely to improve the lifespan and the sealing of the earthen walls.

This investigation aims at finding out a local rain-proof product with greater ability to strengthen external surface of walls and withstand bad weather and water assaults.

\section{Material and Method}

\subsection{Basic Building Material and Basic Equipment}

The carried out experiments are based on the material made up of the following components:

- Raw clay materials: They are extracted from two different sites. The first from the Building and Housing
Centre and the second from Legbassito site. The features are defined, namely calibration, respective contents in sand and clay. After heating at $60{ }^{\circ} \mathrm{C}$, a 500 g sample is selected. This sample is washed out, and then heated at $60{ }^{\circ} \mathrm{C}$ till obtaining constant weight $P$ by sequential weighting process. Then $X$ sand and $Y$ clay of sample contents percentage values are obtained according to the following relation [6-9]:

$$
X(\%)=\frac{100 \cdot P_{f}}{P_{i}} \text { and } Y(\%)=100-X
$$

- The moulds: They are made out of wood and their internal surfaces are lack-painted. They are used to make bricks of sizes (length $\times$ width $\times$ thickness) equals $28 \mathrm{~cm} \times 13 \mathrm{~cm} \times 9.5 \mathrm{~cm}$, with average weight of $7.68 \mathrm{~kg}$ yielding pressure resistance of 5.70 MPa;

- The walls: the experiment integrates construction of three low walls. Each low wall is $1.80 \mathrm{~m}$ long, 1.50 $\mathrm{m}$ high with $0.60 \mathrm{~m}$ corners. The experiment surface of each wall is exposed to the east, heading into the wind and rains of the place where the survey is taking place;

- The basic equipment comprises containers, an isothermal drying oven a vacuum test tube, Sartorius laboratory RTL750 electronic scales, a 1001 type weighting machine, pumice stone, a plastic flexible pipe and water;

- The AFNOR standard sieves: They are used for granular analysis of soil and sea sand stabilization materials. This granular analysis consists in defining the sharing out of the sizes of the constituting grains of the materials [6, 7];

- A Casagrande machine: It serves in the determination of Atterberg limits and enables defining the consistency of clay contained in the soil material in question $[6,7,9]$.

\subsection{Protection Materials}

Some criteria have favoured the choice of the selected protection materials: The first criteria is the local availability of this material; secondly, the material should not disturb the hydrometric balance of the wall, nor affect its thermal comfort. The material 
should help maintain the capillarity of the wall, its evaporation capacity and its aesthetic aspect [5]. The material should be elastic enough to allow dilatation movements of the wall. Otherwise cracking would occur, allowing for water silting; which would still result in unpleasant removal of the protection products, specifically on earthen walls.

(1) Locust bean tree (Parkia biglobosa) fruit husk is the rain-proof and water-proof product selected. Locust bean tree or Parkia biglobosa is a locally common tree in Togo and Benin $[10,11]$. This tree belongs to mimosaceas. The required fruit husk extract is obtained as follows:

- The pod-shaped locust bean mature fruits are gathered;

- The husks are freed from their grains (Fig. 1) then dried;

- The husks are then pounded, crashed and pulverised. Large amount of water is added to this powder (almost $7 \mathrm{~L}$ water $/ \mathrm{kg}$ of powder). The mixture is then left to settle for at least $72 \mathrm{~h}$ (three days);

- Thereafter the husk extract is ready for use. It can thus be applied in two or three layers on the surface of the walls in question;

(2) The mortars: They are made up of the same soil material in question and the rain proof product;

(3) The coatings: They are made and applied on clay bricks and low walls. It is hereinafter called micro coating, any coating applied in tiny layers, i.e., not exceeding $1 \mathrm{~mm}$ thickness. The composition of different types of tested coatings is as follows (from Figs. 2-5 in appendix):

- coating or micro coating made up of plain soil without any additive;

- coating or micro coating made up of three portions of sea sand, two portions of soil;

- coating or micro coating made up of three portions of sea sand for two portions of soil and one portion of cement.

It is noteworthy that the surface of the wall to be protected should be previously polished with pumice stone to facilitate rain water flow. Then the application of protecting materials is proceeded in three stages as follows:

- application of plain coating;

- application of micro coating;

- application of locust bean fruit husk's extract on the coatings.

In order to better appreciate the water assaults' effects on protected surfaces of the low walls, water absorption tests on the one hand, and on the other, water floods wash tests are also carried out.

\subsection{Water Absorption Tests}

Water absorption tests are carried out on segments (bricks) whose surfaces have been coated as indicated above. Each segment weighting initially P1 (right

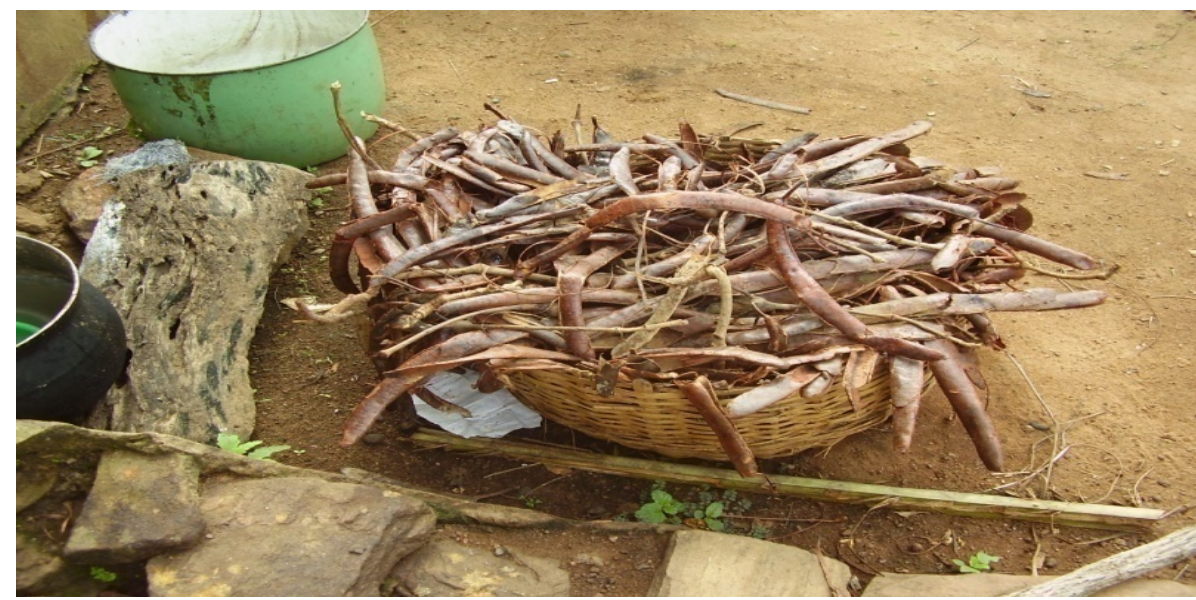

Fig. 1 Picture of locust bean tree (Parkia biglobosa) fruits' emptied husks. 

Tree (Parkia Biglobosa) Used as Protecting Material

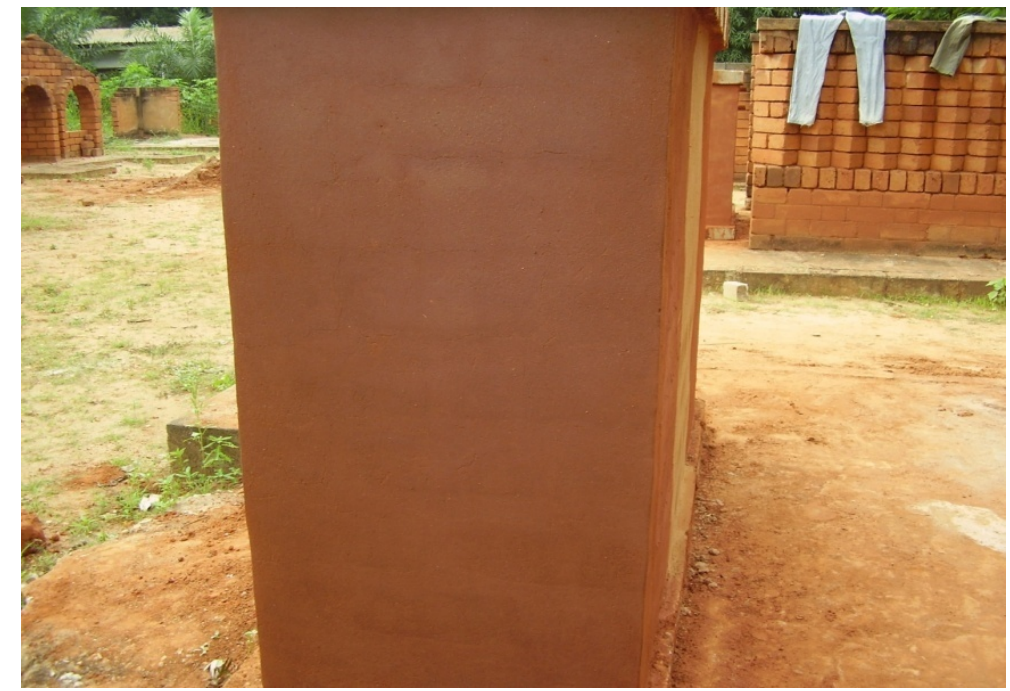

Fig. 2 Micro clay coating, sand and locust bean husk's extract.

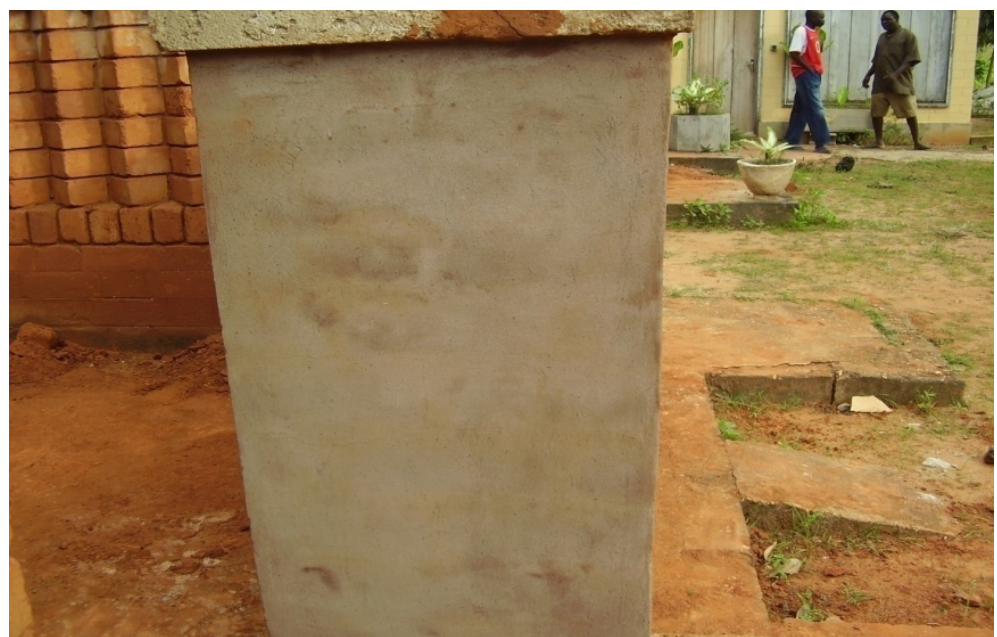

Fig. 3 Micro clay coating, sand, cement and locust bean fruit husk's extract.

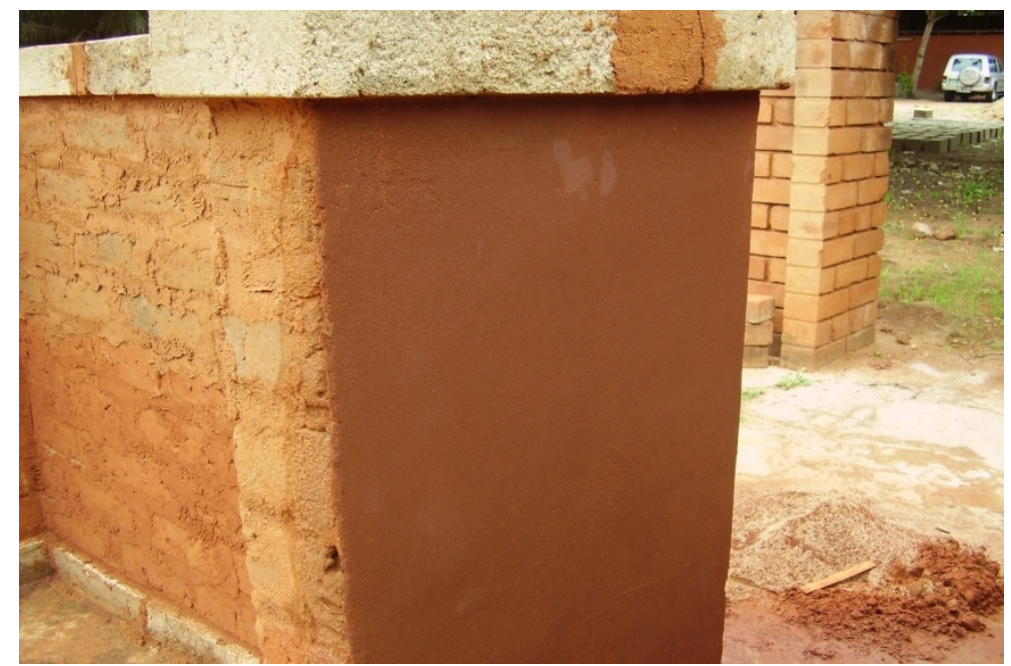

Fig. 4 Clay, sand and locust bean fruit husk's extract. 

Tree (Parkia Biglobosa) Used as Protecting Material

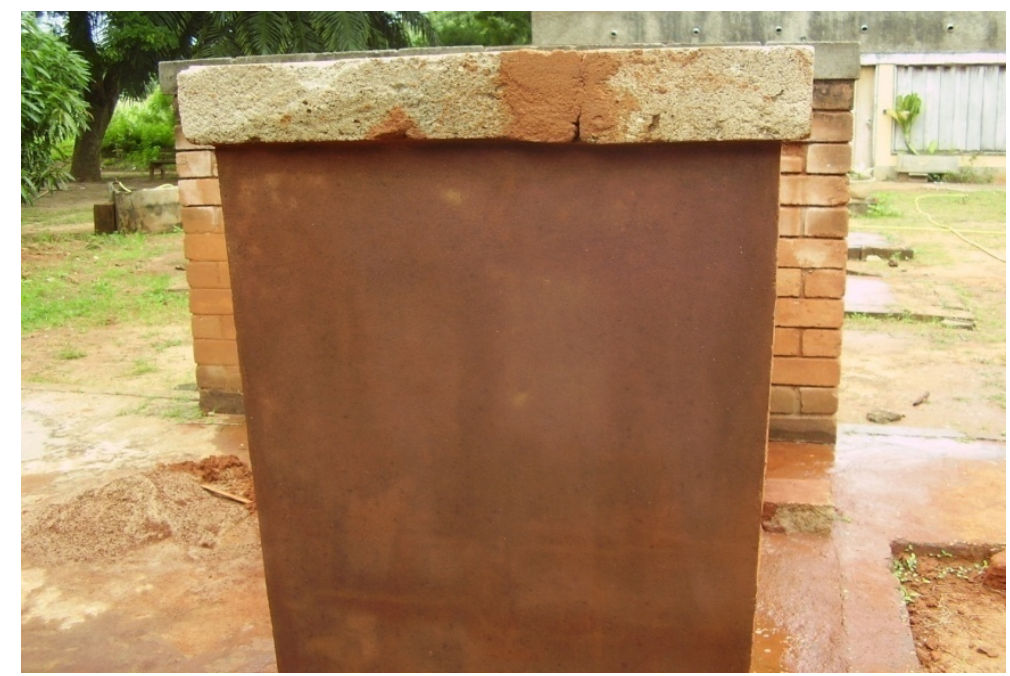

Fig. 5 Clay, sand, cement and locust bean fruit husk's extract.

before immersion) is carefully soaked in water. The progress of the change in weight is then followed, repeating weighting at regular time lapse. However, to avoid total crumbling of the bricks the soaking time has been limited to ten minutes. The immersion lasted for 5 $\mathrm{min}$ in one case (P2) and $10 \mathrm{~min}$ in the other case (P3). In a lapse of time the weight variation corresponds to the quantity of water intake during this time unit.

\subsection{Tests on Low Walls Wash by Water Floods and} Rain.

The protected surfaces of the low walls are submitted to variable intensities of water jets. This way, one simulates a number of rainfalls. Then the aspect of the surfaces of the low walls is analysed.

\section{Results and Discussion}

\subsection{Features of Soil Material Samples}

The soil used in the making of bricks and laying mortars is reddish. Its feature of clay and sand (fine and modulus of fineness) is indicated in Table 1 hereinafter. When leaf mould is taken off, this material contains $59 \%$ of fine clay and $41 \%$ of sand of 1.29 fineness modulus.

Nevertheless, for earthen constructions, it is recommended to use soil containing $45 \%$ fine materials (clay) and 55\% sand [6-9]. Under such circumstances, it has been deemed useful to correct the calibration of available material. Therefore, granular analysis of clay and sand is effected for stabilization sake.

\subsection{Granular Analysis of Clay and Sea Sand}

The outcomes of the two types of analysis are set out in Figs. 6 and 7.

Fig. 6 shows the example of the granular analysis of soil material extracted from Cacaveli site. These results confirm the values obtained in the determination of the basic components: A $40.44 \%$ fine grains for soil sample extracted from Cacaveli site, $46.62 \%$ of soil from Legbassito site. To give an insight, technical documents set a proportion of $8 \%$ to $30 \%$ fine grains [6-9]. This stresses the need to proceed to the right calibration of the two soil materials in question in order to lessen subsequent shrinkage of the mortars during drying process.

The results of the correcting sea sand grains analysis are set out in Fig. 7. They show that this sand is essentially made up of mid-sized and coarse grains with a very tiny portion of fine ones.

Those results enable to screen out suitable sizes of sea sand grains and convenient portions to fill the gap observed in above mentioned initial soils materials (i.e., from Cacaveli) in order to avoid their swelling and assure stability. 


\subsection{Determination of Atterberg Limits of Cacaveli} Site’s Soil Material

The values resulting from parameters defining Atterberg limits are compiled in Table 2. Those values show that the quality of the clay is a beat sandy, with plasticity guaranteeing consistence suiting to the required work, i.e., composition of mortars for the coatings' making.

\subsection{Results of Brick's Water Absorption Analysis}

The values compiled as a result of coated bricks' water absorption tests are compiled in Table 3. The constitution of those protecting materials is specified in column 2.

That series of tests enabled assessment of efficiency of the various types of protections applied on bricks and low walls. Indeed, the results show that the bricks hardly crumble away and lose less weight in the following cases: The micro coating and coatings whose mortars comprise soil, sand, cement and locust bean fruit husk's extract. Likewise, low walls with the same protections as afore-mentioned are less damaged when submitted to water jets. Water flows more readily on the protected surfaces of the low walls painted with locust bean husk's extract, thus confirming the efficiency and rainproof feature of this protection, as evidenced by various values compiled in Table 3.

The average values obtained in those tests (Table 3, column 6) show that the rates in weight losses are higher in the cases of coatings containing locust bean fruit husk extract. Indeed with the plain micro coating (4), the loss is $5.20 \%$ while it amounts to only $0.60 \%$ when containing the extract (7). This gap is important and is evidence to the reliable performance of the locust bean fruit husk extract. The highlighted formula

Table 1 Results of determination of basic components of the samples of the soil used.

\begin{tabular}{lrrrl}
\hline Parameters & $P_{i}(\mathrm{~g})$ & $P_{f}(\mathrm{~g})$ & $X(\%)$ & $Y(\%)$ \\
\hline $\begin{array}{l}\text { Values of } \\
\text { legbassito site }\end{array}$ & 500 & 205 & 41.0 & 59.0 \\
$\begin{array}{l}\text { Values of } \\
\text { Cacaveli site }\end{array}$ & 500 & 206 & 41.4 & 58.6 \\
\hline
\end{tabular}

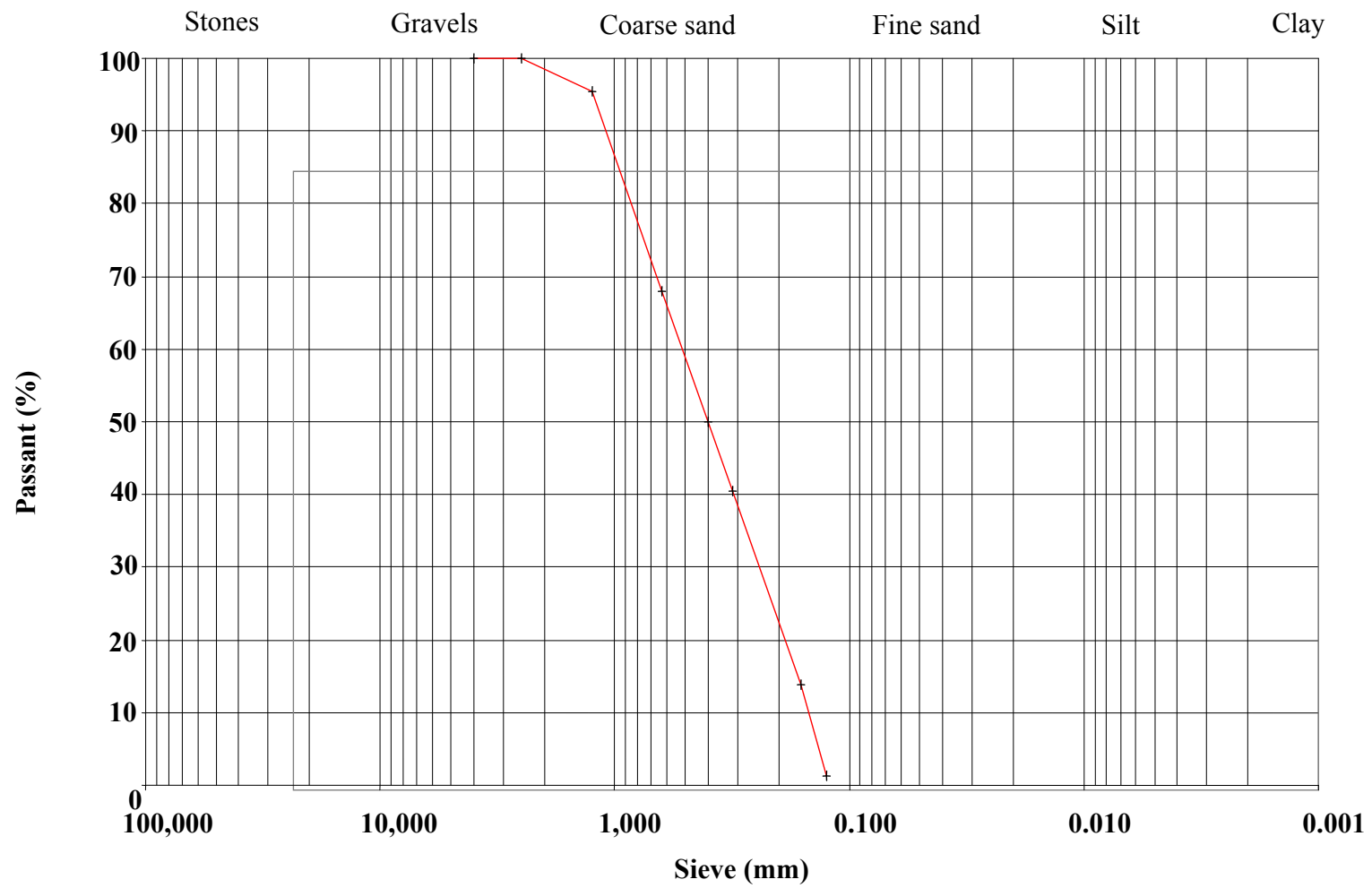

Fig. 6 Results of granular analysis of the Cacaveli soil sample. 
Study on How to Adapt Raw Clay Housing to Climate Change: Locust Bean Tree (Parkia Biglobosa) Used as Protecting Material

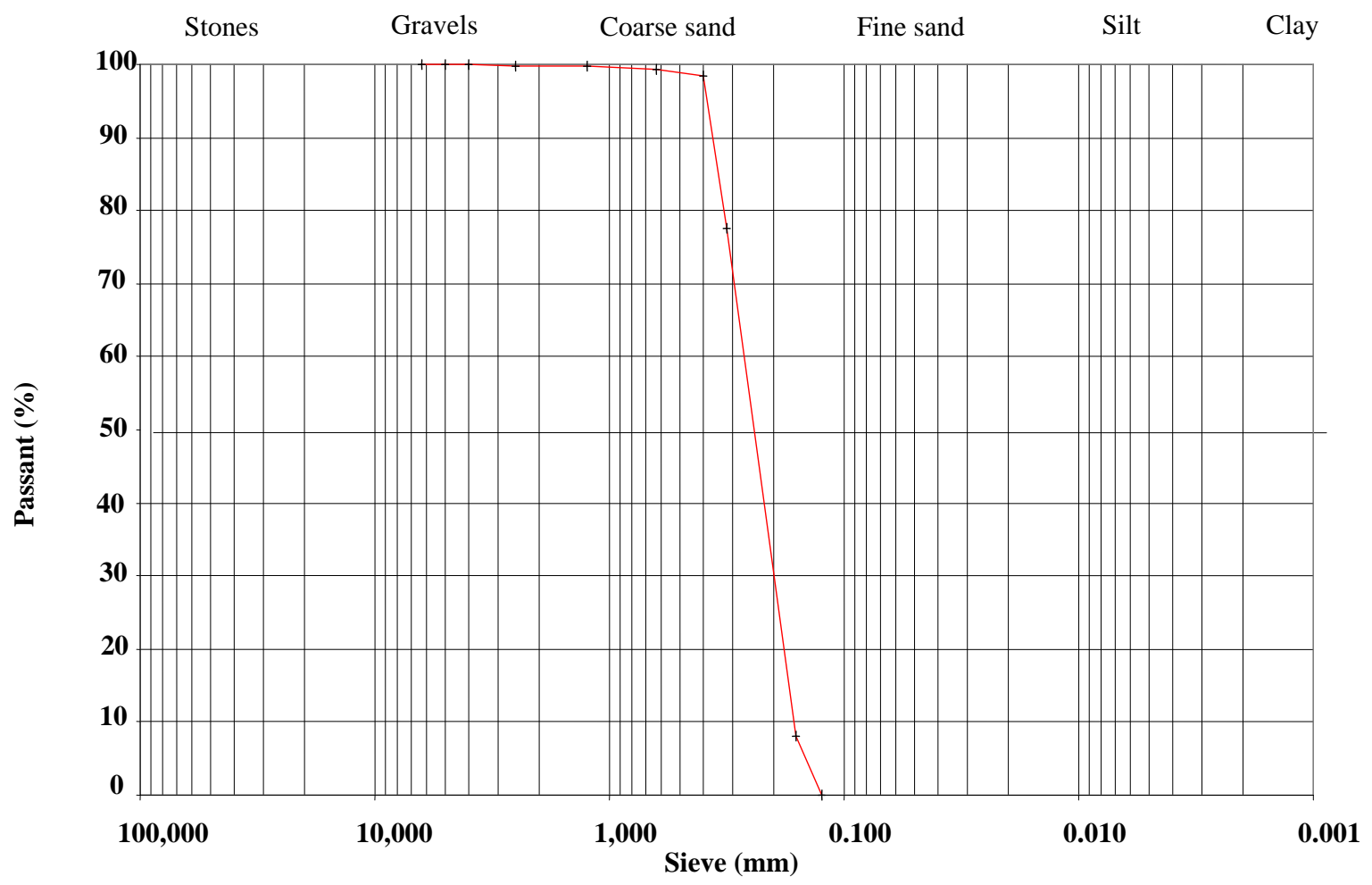

Fig. 7 Outcome of the sea sand granular analysis in question.

Table 2 Recapitulation of Atterberg limits' values computed on the materials in question.

\begin{tabular}{llll}
\hline Parametres & Symbols & Values & Units \\
\hline Water content & W & 28 & $\%$ \\
Limits of liquidity & LL & 28 & $\%$ \\
Limits of plasticity & LP & 20 & $\%$ \\
Plasticity Index & IP & 8 & $\%$ \\
\hline
\end{tabular}

Table 3 Results from bricks segments' water absorption tests and percentages of corresponding average weight losses.

\begin{tabular}{|c|c|c|c|c|c|}
\hline \multirow{2}{*}{$\begin{array}{l}\text { Segments } \\
\text { (bricks) }\end{array}$} & \multirow{2}{*}{$\begin{array}{l}\text { Different formulations of } \\
\text { protections applied }\end{array}$} & \multicolumn{3}{|c|}{ Weight in (t) min } & \multirow[b]{2}{*}{ Average weight loss (\%) } \\
\hline & & $\begin{array}{l}P_{1}(\mathrm{~kg}) \\
t=0 \mathrm{~min}\end{array}$ & $\begin{array}{l}P_{2}(\mathrm{~kg}) \\
t=5 \mathrm{~min}\end{array}$ & $\begin{array}{l}P_{3}(\mathrm{~kg}) \\
t=10 \min \end{array}$ & \\
\hline 1 & \multirow{4}{*}{$\begin{array}{l}(1)=\text { plain clay coating } \\
\text { (thickness= } 0.5 \mathrm{~cm} \text { ) }\end{array}$} & 08.00 & 08.00 & 07.80 & \multirow{4}{*}{2.32} \\
\hline 2 & & 07.70 & 07.70 & 07.60 & \\
\hline 3 & & 07.90 & 07.90 & 07.65 & \\
\hline 1 & & 07.40 & 07.40 & 07.40 & \\
\hline 2 & \multirow[t]{2}{*}{$(2)=$ plain soil coating + cement } & 07.20 & 07.30 & 07.30 & \multirow[t]{2}{*}{1.35} \\
\hline 3 & & 07.30 & 07.30 & 07.30 & \\
\hline 1 & \multirow{3}{*}{$\begin{array}{l}\text { (3) = plain clay coating }+ \text { sea } \\
\text { sand + cement }\end{array}$} & 07.70 & 07.75 & 07.75 & \multirow{4}{*}{1.27} \\
\hline 2 & & 07.50 & 07.50 & 07.50 & \\
\hline 3 & & 07.90 & 07.80 & 07.80 & \\
\hline 1 & \multirow{4}{*}{$(4)=$ micro plain clay coating } & 06.90 & 07.00 & 07.00 & \\
\hline 2 & & 07.05 & 07.00 & 07.00 & \multirow[t]{3}{*}{5.20} \\
\hline 3 & & 06.90 & 07.00 & 07.00 & \\
\hline 1 & & 07.85 & 07.45 & 07.40 & \\
\hline 2 & \multirow{2}{*}{$\begin{array}{l}(5)=\text { micro clay coating }+ \text { sea } \\
\text { sand }\end{array}$} & 07.50 & 07.50 & 07.40 & \multirow[t]{3}{*}{4.35} \\
\hline 3 & & 07.30 & 07.40 & 07.40 & \\
\hline 1 & \multirow{3}{*}{$\begin{array}{l}(6)=\text { micro clay coating + sea } \\
\text { sand + cement }\end{array}$} & 07.40 & 07.40 & 07.40 & \\
\hline 2 & & 07.40 & 07.40 & 07.40 & \multirow{2}{*}{2.70} \\
\hline 3 & & 07.60 & 07.70 & 07.70 & \\
\hline
\end{tabular}




\begin{tabular}{|c|c|c|c|c|c|}
\hline 1 & \multirow{3}{*}{$(7)=(4)+$ locust bean extract } & 7.45 & 7.40 & 7.40 & \multirow{3}{*}{0.60} \\
\hline 2 & & 7.60 & 7.50 & 7.50 & \\
\hline 3 & & 7.60 & 7.50 & 7.50 & \\
\hline 1 & \multirow{2}{*}{$(8)=(5)+$ locust bean extract } & 6.90 & 6.60 & 6.60 & \multirow{2}{*}{0.40} \\
\hline $\begin{array}{l}2 \\
3\end{array}$ & & 7.80 & 7.70 & 7.70 & \\
\hline 1 & \multirow{3}{*}{$(9)=(6)+$ locust bean extract } & 6.50 & 6.20 & 6.20 & \multirow{3}{*}{0.13} \\
\hline 2 & & 7.30 & 7.00 & 7.00 & \\
\hline 3 & & 7.40 & 7.10 & 7.10 & \\
\hline
\end{tabular}

deserves integration to current practices in order to strengthen resistance of walls and consequently reduce recurring reconstructions, and thereby the constraints of the populations in their habits to deploy huge means in reconstructions. Moreover, complementary tests are planned in order to assess the optimal thickness suiting to minimal water absorption and therefore, a low rate of loss in density.

\section{Conclusions}

This survey has first and foremost, allowed to give evidence of the need to protect earthen walls against assaults, namely water floods. In addition, not any quality of soil materials is suitable for long lasting construction works. This is the reason why it has been requisite to analyse the performance of the selected soil materials, for use in construction, referring to the standard mechanical and physical characteristics.

The locust bean tree (Parkia biglobosa) fruit husk extract, with its rainproof character on tested low walls and bricks, appears to show all-round reliable performance as protection product. On this basis, it is henceforth useful to integrate it into efficient protectors of earthen walls.

In consequence, the prospects of this survey find their foundation in the physical and chemical characteristics of this extract, and possible alternatives in Construction and Public Works Sector, as well as in any other fields, in view to optimizing its different applications.

\section{References}

[1] Document of the National Housing Strategy, Ministry of Urban Development and Housing, Lomé, 2010. (in French)

[2] J.A. Silva, Research on the Protection of the Surface of the Mud Walls, Centre for Construction and Housing, UNDP Project TOG-72-007, 1974, pp. 1-35. (in French)

[3] G.H, Padenou, M. Barrue-Pastor, Architecture, Landscape and Betammaribé Society of Togo, University Press of Miral, Duvergier, 2006, pp. 196-230.

[4] L. Fontaine, R. Anger, Building with Earth: From the Grain of Sand to the Architecture, City of Science and Industry, Belin Edition, 2009, p. 224.

[5] J.P. Oliva, The Bioclimatic Design, Living Earth Edition, Ecological Isolation: Design, Materials, Implementation, Living Earth, 2001, p. 224.

[6] R. Dupain, R. Lanchon, J.C. Saint-Arroman, A. Capliez, Aggregates, Soil, Cement and Concrete, Characterization of Civil Engineering Materials by Laboratory Tests, 3rd ed., Editions Casteilla, 2004, p. 236.

[7] AFNOR (French Association for Standardization) Standard EN 933-8, Tests for Geometrical Properties of Aggregates-Part 8: Assessment of Fines, Sand Equivalent, AFNOR Editions, Paris, 1999, p. 16.

[8] C. Mathieu, F. Pieltain, Physical Soil Analysis: Selected Methods, Edition Tech. \& Doc., Lavoisier, 1998, p. 274.

[9] G. Dreux, J. Festa, New Guide of Concrete and Its Constituents, 8th ed., Eyrolles, Paris, 1998, p. 416.

[10] S.D.V. Alihonou, Thesis for Agronomist Engineer Diploma, University of Abomey-Calavi, Bénin, 2006, p. 55.

[11] M.L. Guttierez, P. Maïzi, M. Nago, J. Hounhouingan, Production and marketing of Fon afiti in Abomey-Bohicon region in Benin, Academic Dissertatio, Benin, 2000, p. 123. 